\title{
TINJAUAN STABILITAS TANGGUL PENAHAN GELOMBANG PADA PANTAI DOFIOR KOTA SORONG
}

\author{
Muhammad Tasmin ${ }^{1)}$, Hendrik Pristianto ${ }^{2)}$ \\ 1) Mahasiswa S-1 Program Studi Teknik Sipil Universitas Al-Amin Muhammadiyah Kota Sorong \\ 2) Dosen Pengajar Program Studi Teknik Sipil Universitas Al-Amin Muhammadiyah Kota Sorong
}

\begin{abstract}
Abstrak
Pantai dofior adalah pantai yang mempunyai potensi pariwisata yang cukup besar. Pantai yang berada di sebelah barat salah satu kota paling barat di daratan papua ini terkenal akan keindahan pemandangan panorama laut serta keindahan matahari terbenam (sunset) menjelang senja dan jajanan kuliner yang berada disekitar pantai tersebut. Di pantai ini terdapat bangunan pengaman pantai yaitu dinding/tembok penahan gelombang yang membatasi antara daratan dan daerah pantai. Di kaki bangunan tersebut terjadi abrasi oleh gelombang. Penulisan ini bermaksud untuk mengetahui stabilitas tanggul penahan gelombang apakah masih dalam keadaan aman. Dan alternatif pengamanan pantai difior yang sesuai untuk melindungi dari abrasi. Analisa yang dilakukan dalam penulisan ini antara lain analisa pasang surut untuk menentukan elevasi acuan desain bangunan, peramalan gelombang jamjaman selama 3 tahun (2008-2010) yang di peroleh dari stasiun BMKG Bandara DEO kota Sorong untuk mendapatkan tinggi dan perioda gelombang. Dari hasil analisa, ternyata tanggul penahan gelombang tersebut tidak aman terhadap gaya geser akan tetapi aman terhadap guling. Oleh sebab itu diperlukan perencanaan lebih mendetail agar menjaga kestabilan pantai.
\end{abstract}

Kata Kunci : Pantai , Gelombang, Tanggul, Stabilitas

\section{PENDAHULUAN}

\subsection{Latar Belakang}

Pantai adalah sebuah bentuk geografis yang terdiri dari pasir, dan terdapat di daerah pesisir laut. Daerah pantai menjadi batas antara daratan dan perairan laut. Pantai juga merupakan tempat bermuaranya sungai-sungai serta saluran pembuang yang baik secara alami dan buatan. Potensi yang terdapat di daerah pantai antara lain dapat dimanfaatkan sebagai kepentingan dalam bidang pariwisata, perikanan, pelabuhan, dan pemukiman.

Salah satu pantai yang terdapat di kota sorong yang mempunyai potensi pariwisata cukup besar adalah pantai dofior. Pantai yang berada di sebelah barat salah satu kota paling barat di daratan papua ini terkenal akan keindahan pemandangan panorama laut serta keindahan matahari terbenam (sunset) menjelang senja dan jajanan kuliner yang berada disekitar pantai tersebut.

Dilihat dari situasi, pantai dofior merupakan salah satu daerah yang terancam masalah erosi pantai. Erosi pantai dapat menimbulkan kerugian yang sangat besar dengan rusaknya kawasan pemukiman dan fasilitas-fasilitas yang ada di daerah tersebut. Untuk menanggulangi erosi pantai langkah pertama yang harus dilakukan adalah mencari penyebab terjadinya erosi. Dengan mengetahui penyebabnya, selanjutya dapat ditentukan cara penanggulangannya, yang biasanya adalah dengan membuat bangunan pelindung pantai atau menambah suplai sedimen.

Bangunan pelindung pantai yang ada di daerah pantai dofior saat ini adalah tembok/dinding penangkal abrasi yang panjangnya $1 \mathrm{~km}$, yang tingginya sekitar 1,5 meter dari badan jalan raya, memiliki beberapa titik anak tangga. Bagian atas tembok tersebut memiliki lebar sekitar 1 meter, yang terbagi dalam dua tangga yang selisih tingginya sekitar 30 sentimeter. Tetapi, Di pantai Dofior pada saat gelombang ekstrim terjadi, air laut dapat terhempas ke daratan sampai ke jalan raya sehingga dapat menggangu kenyamanan lalu lintas di daerah tersebut dan pada kaki bangunan pengaman pantai/tanggul tersebut sudah mulai mulai terjadi erosi. 


\subsection{Rumusan Masalah}

Berdasarkan latar belakang diatas, maka permasalahan yang akan di bahas dalam tugas akhir ini yaitu :

1. Apakah tanggul penahan ombak tersebut masih dalam keadaan stabil melihat sudah mulai terjadi erosi pantai pada kaki bangunan.

2. Bagaimana perencanaan pengamanan pantai dofior yang sesuai untuk melindungi dari abrasi

\subsection{Batasan Masalah}

Dalam tugas akhir ini untuk memperjelas permasalahan dan memudahkan dalam menganalisa, maka penulis membatasi permasalahan yaitu sebagai berikut :

1. Menentukan komponen utama pasang surut dan elevasi yang penting.

2. Melakukan peramalan gelombang dengan data angin.

3. Menghitung stabilitas bangunan pengaman pantai yang sudah ada.

4. Menentukan dan merencanakan jenis bangunan pengaman pantai

5. Tidak memperhitungkan biaya dalam perencanaan pembangunan

\subsection{Tujuan Penelitian}

Adapun tujuan dari pembahasan tugas akhir ini adalah :

1. Untuk mengetahui bagaimana kondisi eksisting pantai dofior kota sorong.

2. Untuk mengetahui alternatif perencanaan bangunan pelindung pantai.

\section{TINJAUAN PUSTAKA}

\subsection{Hindcasting Gelombang}

Peramalan gelombang disebut juga Hindcasting gelombang jika didasarkan pada kondisi meteorologi masa lalu dan forecasting gelombang jika didasarkan pada kondisi perkiraan. Metode peramalan gelombang dapat dibedakan atas metode peramalan gelombang laut dalam dan peramalan gelombang laut dangkal. Perbedaan kedua metode ini adalah dalam metode peramalan laut dangkal diperhitungkan faktor gesekan antar gerak air di dasar laut, yang mengurangi tinggi gelombang yang terbentuk. Dalam metode peramalan gelombang laut dalam, gerak gelombang terjadi di bagian atas perairan tanpa dipengaruhi dasar laut (karena pada laut dalam, jarak vertikal dari dasar laut ke permukaan air relatif jauh). Jadi gelombang dan pembentukan gelombang di laut dalam tidak dipengaruhi oleh keadaan di dasar laut (CECR,1984).

Kriteria laut dalam dan laut dangkal berdasarkan perbandingan panjang gelombang (L), dan kedalaman dasar laut (d), bukan pada harga mutlak kedalaman perairan.

Peramalan gelombang dilakukan dengan mengikuti metoda yang diberikan dalam Shore Protection Manual (Coastal Engineering Research Center, US Army Corp of Engineer).

\subsection{Pasang Surut}

Pasang surut adalah fluktuasi muka air laut karena adanya gaya tarik bendabenda di langit (Triatmojo, 1999), terutama matahari dan bulan terhadap massa air laut dibumi . Meskipun massa bulan jauh lebih kecil dari massa matahari, tetapi karena jaraknya terhadap bumi jauh lebih dekat, maka pengaruh gaya tarik bulan terhadap bumi lebih besar dari pada pengaruh gaya tarik matahari. Gaya tarik bulan mempengaruhi pasang surut adalah 2,2 kali lebih besar dari pada gaya tarik matahari. Pengetahuan tentang pasang surut adalah penting di dalam perencanaan bangunan pantai dan pelabuhan. Elevasi muka air tertinggi dan terendah sangat penting untuk merencanakan bangunan bangunan tersebut.

\subsection{Definisi Elevasi Muka Air}

Beberapa elevasi tersebut adalah sebagai berikut (Triatmojo, 1999):

a. Muka air pasang tinggi (high water level), muka air tertinggi yang dicapai pada saat air pasang dalam satu siklus pasang surut.

b. Muka air rendah (low water level). kedudukan air terendah yang dicapai pada saat air surut dalam satu siklus pasang surut.

c. Muka air tinggi rerata (mean high water level, MHWL), adalah rerata dari muka air tinggi selama periode 19 tahun. 
d. Muka air rendah rerata (mean low water level, MLWL), adalah rerata dari muka air rendah selama periode 19 tahun.

e. Muka air laut rerata (mean sea level, MSL), adalah muka air rerata antara muka air tinggi rerata dan muka air rendah rerata.

f. Muka air tinggi tertinggi (highest high water level, HHWL), adalah air tertinggi pada saat pasang surut purnama atau bulan mati.

g. Air rendah terendah (lowest low water level, LLWL), adalah air terendah pasa saat pasang surut purnama atau bulan mati.

\subsection{Bangunan Pantai}

Bangunan pelindung pantai adalah bangunan pantai digunakan untuk melindungi pantai dari gelombang dan arus. Ada beberapa cara yang dapat dilakukan untuk melindungi pantai, yaitu :

1. Memperkuat/melindungi pantai agar mampu menahan serangan gelombang.

2. Mengubah laju transport sedimen sepanjang pantai

3. Mengurangi energi gelombang yang sampai ke pantai,

4. Reklamasi dengan menambah suplai sedimen ke pantai atau dengan cara lain.

Bentuk konservasi pantai dengan cara pembuatan struktur pengamanan pantai buatan adalah dengan hard structure (struktur keras) dan soft structure (struktur lunak). Struktur keras didesain dengan kondisi yang stabil dan tetap, mampu menahan ombak, mampu menahan arus dan transport sedimen secara penuh. Oleh karena itu struktur keras memberikan pengaruh yang lebih besar terhadap perpindahan pasir atau sedimentasi secara alami. Yang termasuk dalam struktur keras adalah : groin, revetment, seawalls dan breakwater. Sedangkan alternatif pemakian struktur lunak diharapkan merupakan struktur yang dapat bergerak dinamis, seiring dengan kondisi ombak dan arus. Contoh struktur lunak antara lain: beach nourishment dan penghijauan daerah pantai untuk meningkatkan stabilitas pantai.

\subsection{Kontrol Stabilitas Tanggul}

I. Stabilitas tanggul terhadap guling

Stabilitas tanggul tehadap gaya-gaya yang bekerja pada tanggul akan dapat ditinjau bila tanggul dianggap dapat terguling, dengan menganggap bahwa tubuh tanggul merupakan suatu kesatuan. Gaya-gaya yang bekerja pada tanggul dan berbahaya terhadap guling adalah :

1. Gaya akibat beban sendiri.

2. Tekanan hidrostatis

3. Gempa bumi

Konstruksi tanggul akan aman terhadap guling, apabila memenuhi persamaan berikut ini (oehadijono, 1993) :

$$
F k=\frac{M T}{M G} \geq 1,5
$$

$$
\text { Dimana : }
$$

MT = Momen Tahan

MG = Momen Guling

$\mathrm{Fk} \quad=$ Faktor Keamanan

II. Kontrol Terhadap Geser

Untuk mengetahui konstruksi tidak mengeser dapat dihitung dengan menggunakan rumus sebagai berikut : (Oehadijono,1993).

$$
F k=\frac{\sum V \cdot f}{\sum H}>1,2
$$

$$
\text { Dimana : }
$$

$\mathrm{Fk} \quad=$ Faktor Keamanan

$\sum V \quad=$ Jumlah gaya-gaya vertikal

$\sum H \quad=$ Jumlah gaya-gaya horizontal

\section{METODE PENELITIAN}

\subsection{Lokasi Penelitian}

Dalam penulisan tugas akhir ini penelitian yang dilakukan, secara umum dilaksanakan di kota sorong dengan mengambil lokasi penelitian yaitu di pantai dofior tembok berlin.

\subsection{Metode Pengumpulan Data}

Teknik yang digunakan dalam rangka pengumpulan data dalam rangka tinjauan stabilitas tanggul penahan gelombang pada pantai dofior kota sorong adalah dengan mencari data-data yang diperlukan, baik itu data primer maupun sekunder. Yaitu sebagai berikut :

1. Data primer

Data primer adalah data yang diperoleh dengan cara melakukan peninjauan atau survey langsung di 
lapangan. Seperti dokumentasi berupa foto kondisi pantai di lokasi penelitian.

2. Data sekunder

Data sekunder adalah data-data yang diperoleh dari instansi-instansi terkait untuk penelitian.

\subsection{Analisis Data}

Dalam penelitian ini analisa data yang dilakukan antara lain sebagai berikut :

1. Analisis data Angin

2. Analisis data pasang surut

\subsection{Diagram Alir Penelitian (Flow Chart)}

Penelitian yang dilakukan secara garis besar mengikuti diagram alir sebagai berikut :

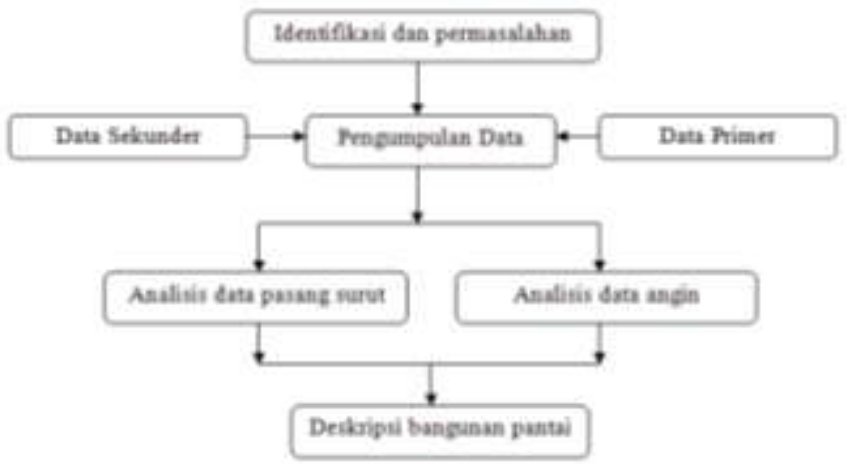

Gambar 1 diagram alir pelaksanaan penelitian

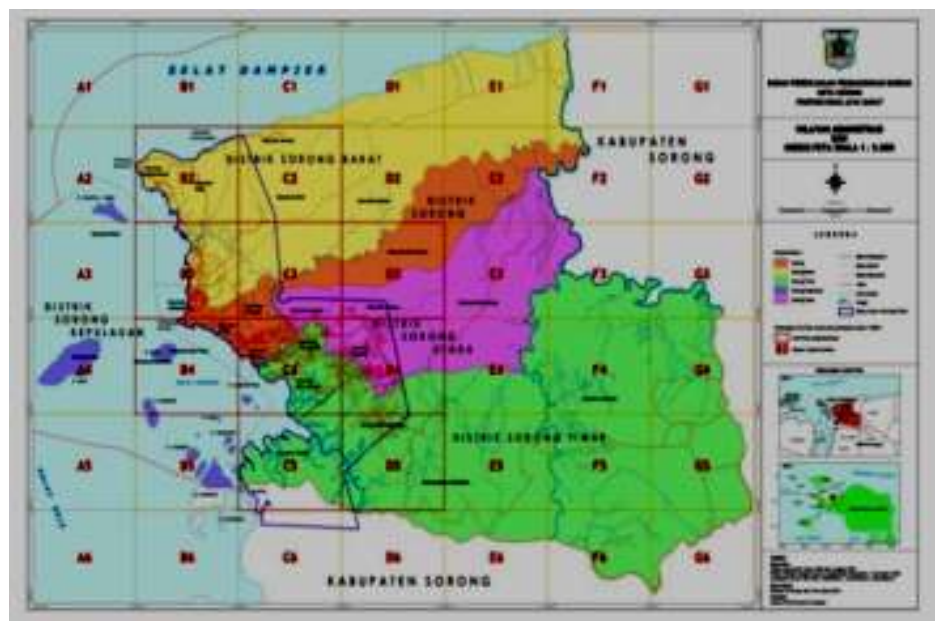

Gambar 2 Peta Kota Sorong

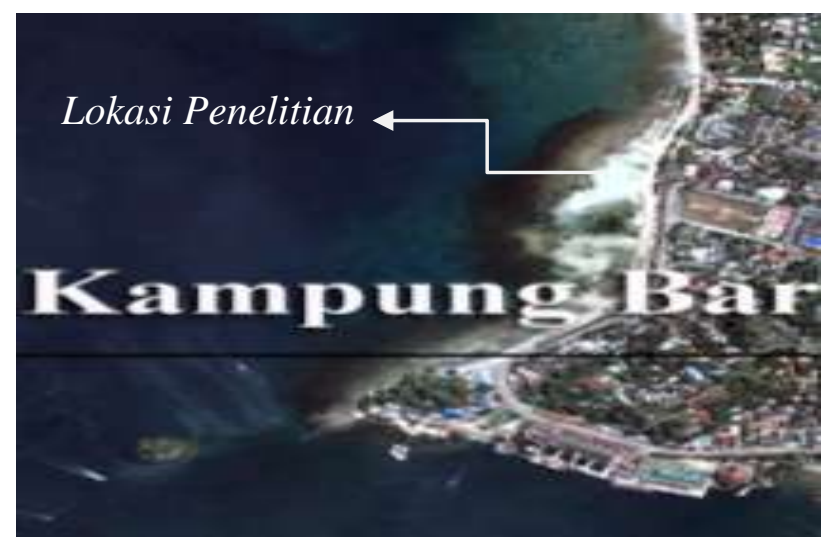

Gambar 3 lokasi penelitian

\section{ANALISA DAN PEMBAHASAN \\ 4.1 Analisis Data Pasang Surut}

Kegiatan analisis data pasang surut bertujuan untuk mendapatkan parameter-parameter yang diperlukan bagi perencanaan suatu bangunan pantai. Parameter-parameter tersebut adalah :

a. Konstanta pasang surut

b. Elevasi muka air acuan

Data pasang surut di peroleh dari Dinas Hidro-Oceanografi TNI-AL dengan lokasi pada pelabuhan sabandar dekat dengan lokasi penelitian yang yang digunakan dengan Metode Kuadral Terkecil (Least Square) pengolahan data selama 29 hari dari tanggal 1 Desember 2010 sampai dengan 29 Desember 2010. Berdasarkan Pengolahan data pasang surut tersebut diperoleh parameter amplitudo dan beda fase dari masingmasing komponen pasang surut yaitu sebagai berikut :

Tabel 1 Komponen utama pasang surut kota sorong

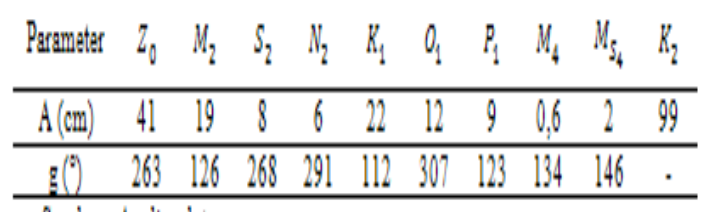

Sumber : Analisa data

Dari nilai amplitudo yang didapat, maka dapat dihitung nilai Formzahl (F) untuk menentukan karakteristik type/sifat pasang surut yang terjadi pada daerah tersebut dengan 
$\mathrm{F} \quad=\frac{K_{1}+O_{1}}{M_{2}+S_{2}}=\frac{22+12}{41+19}=0,57$

Dengan nilai $F$ (Formzahl) tersebut maka tipe pasang surut berada dalam interval $0,25<\mathrm{F}<1,5$, maka di kategorikan pasang surut tersebut termasuk tipe campuran dominan ganda.

Berdasarkan amplitudo komponen pasang surut tersebut di atas maka dapat ditentukan atau dihitung acuan elevasi muka air (Tabel 5) sebagai berikut :

Tabel 2 elevasi acuan pasang surut

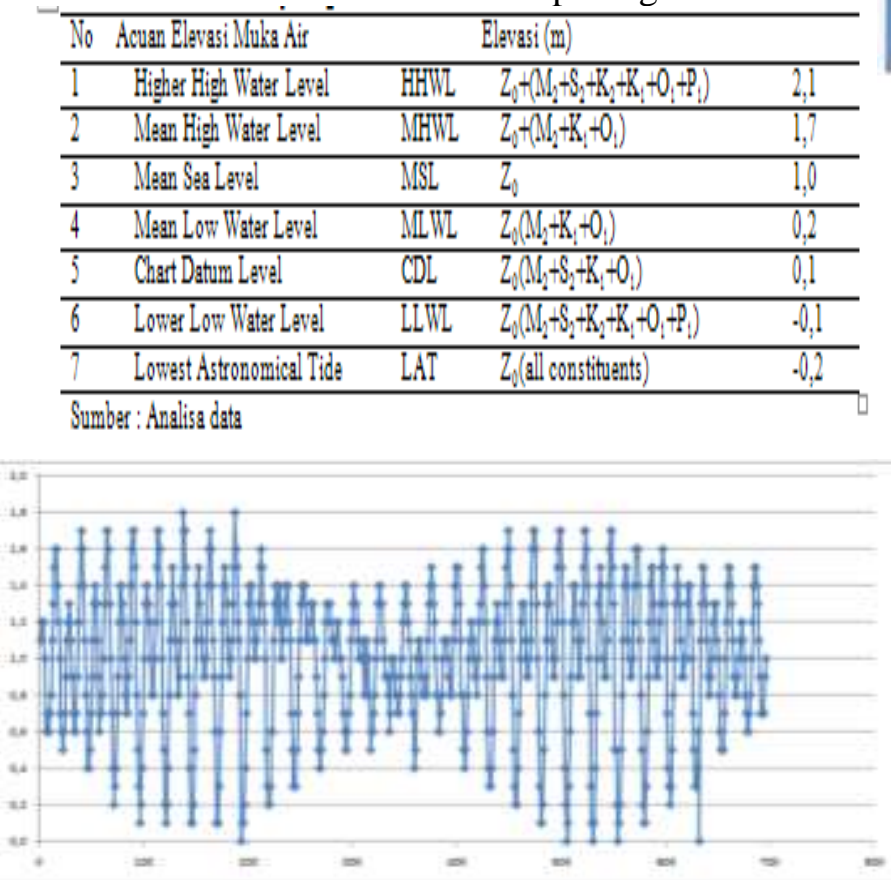

Gambar 5 grafik pasang surut tanggal 1 Desember 2010-29 Desember 2010

\subsection{Analisa Data Angin}

Data angin yang diperoleh berasal dari Pos Pengamatan BMKG Bandara DEO Sorong yaitu data kecepatan dan arah angin jamjaman selama 3 tahun yaitu dari tahun 2008, 2009, dan 2010. Data angin tersebut digunaka untuk perhitungan fetch efektif dan peramalan gelombang.

\subsubsection{Perhitungan Fetch Efektif}

Fetch efektif dihitung berdasarkan masing-masing arah mata angin utama yaitu utara, timur laut, timur, tenggara, selatan, barat daya, barat, dan barat laut dimana satu arah mencakup sektor $45^{\circ}$. Pada pantai
Dofior kota Sorong tidak ada pembangkitan gelombang dari arah daratan, yaitu dari arah Utara, Timur laut, Timur, Tenggara dan selatan, maka panjang fetch efektifnya adalah nol.

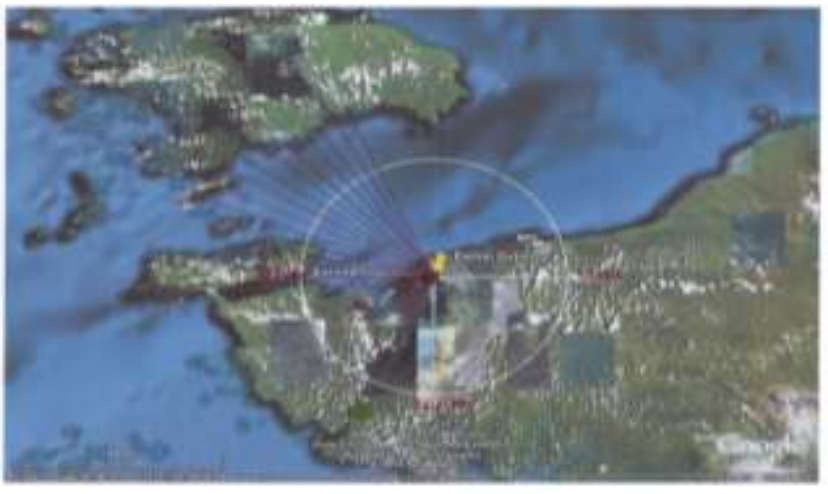

Gambar 6 Perhitungan Fetch efektif pantai Dofior

Tabel 3. Resume hasil perhitungan Fetch Efektif Pantai Dofior

\begin{tabular}{lc}
\multicolumn{1}{c}{ Arah Utama } & Fetch Efektif $(\mathrm{km})$ \\
\hline Utara & 0 \\
Timur Laut & 0 \\
Timur & 0 \\
Tenggara & 0 \\
Selatan & 0 \\
Barat Daya & 21,41 \\
Barat & 38,11 \\
Barat Laut & 68,91 \\
\hline
\end{tabular}

Sumber : Analisis Data

\subsubsection{Peramalan Gelombang (hindcasting)}

Dari data angin jam-jaman dilakukan peramalan gelombang (hindcasting), dimana hasil perhitungan gelombang dapat dlihat pada tabel berikut ini:

Tabel 4 Arah, Tinggi dan Periode Gelombang Tahunan Terbesar Hasil Peramalan Data Angin Tahun 2008-2010

\begin{tabular}{|c|c|c|c|c|c|c|c|}
\hline \multirow[t]{2}{*}{ Anh } & \multicolumn{7}{|c|}{ Tingei Geiambang (m) } \\
\hline & $=0.2$ & $0,20,4$ & $0,40,6$ & $0,5-0,1$ & $0,8-1,0$ & $x=1,0$ & Toal \\
\hline पtan $(N)$ & 0 & 0 & 0 & 0 & 0 & 0 & 0 \\
\hline Timar L.avt (NE.) & 0 & 0 & 0 & 0 & 0 & 0 & 0 \\
\hline Tinsar (f) & 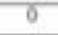 & 8 & 8 & 8 & 0 & 0 & 8 \\
\hline Temisara (SE) & 0 & 0 & 0 & 0 & 5 & 0 & 0 \\
\hline Selatan (S) & 0 & 0 & 0 & 0 & 0 & 0 & 0 \\
\hline Harat Daya(SW) & 3 & 361 & 306 & 179 & 14 & 0 & 1365 \\
\hline 8 Barat (W) & 0 & 407 & 944 & 723 & 79 & II & $21 \% 0$ \\
\hline Barat Laur (NW) & 0 & 160 & 355 & 301 & 130 & 49 & 978 \\
\hline Sab.Iotal & 5 & Inos & 2108 & $20 \theta$ & 221 & 60 & 470 \\
\hline $\begin{array}{l}\text { Tidak Bertelemba } \\
\text { (calm) }\end{array}$ & & & & & & - & $21+83$ \\
\hline Tidak Tecutur & & & & & & $m$ & II \\
\hline Total & & & & & & $=$ & 2632 \\
\hline
\end{tabular}


Tabel 5 Persentase kejadian Gelombang berdasarkan Interval dan Arah

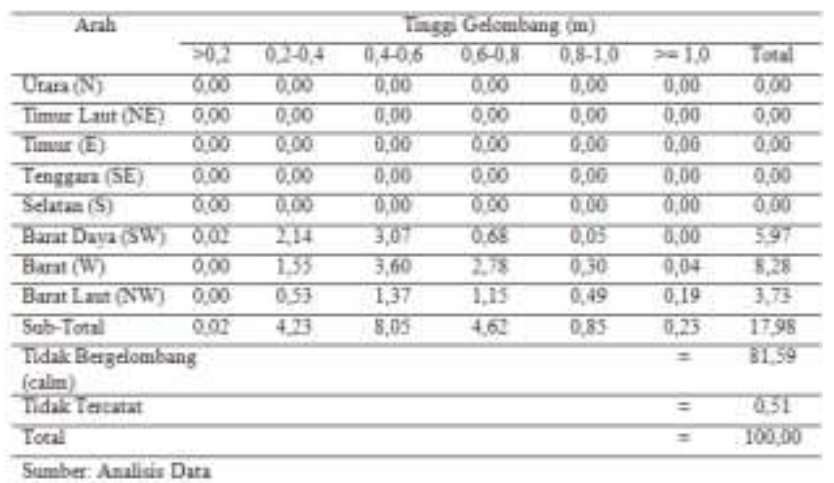

Dari tabel diatas dapat disimpulkan bahwa kejadian gelombang dari tahun 2008 sampai 2010 menunjukkan bahwa kondisi tidak bergelombang lebih dominan yaitu $81,59 \%$ dan kondisi gelombang yang dominan pada arah Barat yaitu sebesar 8,28\% dan Barat Daya yaitu 5,97\%

Tabel diatas dapat disajikan dalam bentuk diagram untuk mengetahui karakteristik gelombang yaitu dengan diagram gelombang dengan interval $0,2 \mathrm{~m}$ seperti yang terlihat pada gambar berikut :

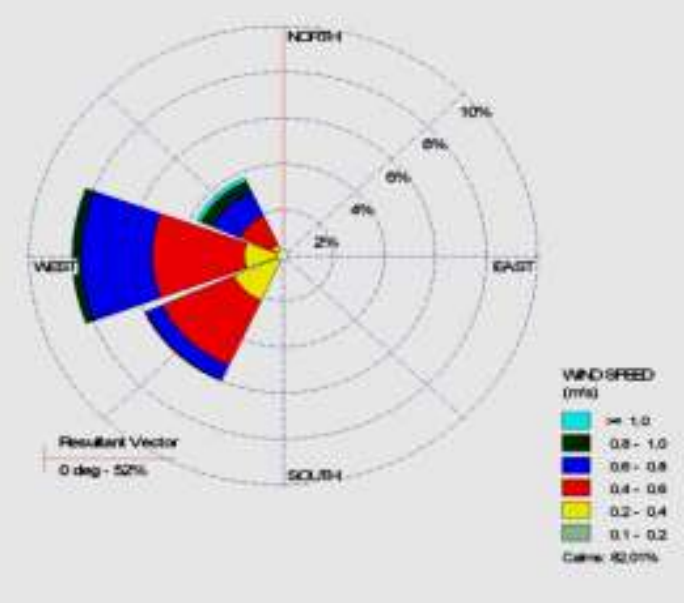

Gambar 7 Mawar Gelombang Tahun 20082010

\subsection{Bangunan Yang Ada Saat Ini.}

Bangunan yang ada saat ini adalah dinding laut sepanjang $1,1 \mathrm{~km}$ yang membatasi antara daratan dan lautan. Lihat gambar . di kaki bangunan tersebut sudah mulai tergerus oleh gelombang yang sewaktu-waktu dapat terjadi kerusakan yang lebih parah hingga roboh dan jalan semakin terancam. Di pantai dofior terdapat 2 bentuk dimensi tanggul yaitu sebagai berikut :

1. Tampang lintang pertama dari tanggul

Tampang lintang pertama dari tanggul tembok berlin dapat dilihat pada gambar di bawah ini :

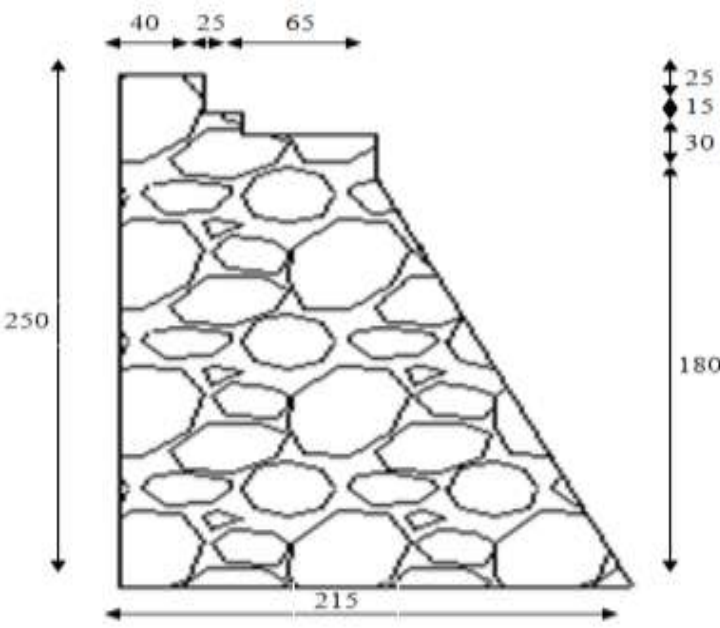

Gambar 8 Tampang lintang pertama dari tanggul tembok berlin

Kontrol stabilitas tanggul

1. Stabilitas tanggul terhadap gaya-gaya yang bekerja pada tanggul

Stabilitas tanggul terhadap gaya-gaya yang bekerja pada tanggul akan dapat ditinjau bila tanggul dianggap dapat terguling, dengan menganggap bahwa tubuh tanggul merupakan suatu kesatuan. Gaya-gaya yang bekerja pada tanggul dan berbahaya terhadap guling yaitu:

a. Gaya akibat beban sendiri.

b. Tekanan Hidrostatis

c. Gempa Bumi

a. Berat sendiri tanggul

$\mathrm{W}=$ Luas $\times \gamma$ tanah

$W_{1}=2,50 \times 0,40 \times 2,00=2,00 \mathrm{t} / \mathrm{m}$

$W_{2}=2,25 \times 0,25 \times 2,00=1,125 \mathrm{t} / \mathrm{m}$

$W_{3}=2,10 \times 0,65 \times 2,00=2,73 \mathrm{t} / \mathrm{m}$

$W_{4}=1 / 2 \times 0,85 \times 1,80 \times 2,00=1,53$

$\mathrm{t} / \mathrm{m}$

Jadi $\mathrm{W}$ total $=W_{1}+W_{2}+W_{3}+W_{4}=$ $7,385 \mathrm{t} / \mathrm{m}$

b. Tekanan Hidrostatis

$W H_{1}=1 / 2 \times \gamma$ air $\times h^{2}$

$W H_{1}=1 / 2 \times 1,025 \times 1,8^{2}=1,66 \mathrm{t} / \mathrm{m}$

$W_{5}=1 / 2 \times \gamma$ air $\times \mathrm{a} \times \mathrm{t}$

$W_{5}=1 / 2 \times 1,025 \times 0,85 \times 1,8=0,78 \mathrm{t} / \mathrm{m}$ 
c. Pengaruh gempa

Dengan mengambil harga koefisien gempa 0,20 sampai 0,35 maka komponen-komponen horizontal beban gempa di hitung sebagai berikut :

$$
\boldsymbol{m} \cdot \boldsymbol{a}=\boldsymbol{e} \cdot(\boldsymbol{m} \cdot \boldsymbol{g})
$$

Dimana :

$$
\begin{array}{ll}
\mathrm{M} & =\text { massa } \\
\mathrm{A} & =\text { percepatan horizontal } \\
\mathrm{E} & =0,1-0,35 \\
\mathrm{G} & =\text { Grafitasi }
\end{array}
$$

Dengan mengambil $m \cdot a=F$ dan

$$
m \cdot g=G=W
$$$$
F_{1}=2 \times 0,35=0,7 \mathrm{t} / \mathrm{m}
$$$$
F_{2}=1,125 \times 0,35=0,394 t / m
$$$$
F_{3}=2,73 \times 0,35=0,956 \mathrm{t} / \mathrm{m}
$$$$
F_{4}=1,53 \times 0,35=0,535 \mathrm{t} / \mathrm{m}
$$$$
F_{5}=0,78 \times 0,35=0,273 \mathrm{t} / \mathrm{m}
$$

2. Kontrol Terhadap Stabilitas Guling

Konstruksi tanggul akan aman terhadap guling, apabila memenuhi persamaan berikut :

$$
\begin{aligned}
& \text { Fk }=\frac{\boldsymbol{M} \boldsymbol{T}}{\boldsymbol{M G}} \geq \mathbf{1 , 5 0} \\
& \text { Dimana : } \\
& \text { MT }=\text { Momen Tahan } \\
& \text { MG }=\text { Momen Guling } \\
& \text { Fk } \quad=\text { Faktor Keamanan }
\end{aligned}
$$

\begin{tabular}{|c|c|c|}
\hline $\begin{array}{l}\text { Gaya } \\
\text { ela? }\end{array}$ & $\begin{array}{l}\text { Tank } \\
\text { (m) }\end{array}$ & $\begin{array}{l}\text { Yonen } \\
(\mathrm{ta})\end{array}$ \\
\hline \multicolumn{3}{|c|}{ Ahluat Bebans Sendini } \\
\hline$i \mathrm{~S}_{2}=2.00$ & $x-0,20$ & 0.4 \\
\hline$w_{2}=1,125$ & $x=0,525$ & 0,591 \\
\hline$w_{2}-2,73$ & $x=0.975$ & 2,662 \\
\hline$w_{1}=1.53$ & $x=1,5833$ & 2422 \\
\hline \multicolumn{3}{|c|}{ Abbat Gaya Hudrontaria } \\
\hline$W_{3}=0,78$ & $x-1,2669$ & 1,436 \\
\hline$w H_{1}=1.66$ & $y=0,60$ & 0.996 \\
\hline \multicolumn{3}{|c|}{ Abbat Bebun Gespa } \\
\hline$F_{1}=0,7$ & $y=1,25$ & 0.575 \\
\hline$F_{2}=0.394$ & $y=1,125$ & 0,443 \\
\hline$F_{3}=0.956$ & $y=1,05$ & 1,004 \\
\hline$F_{4}=0,535$ & $y=0,60$ & 0.321 \\
\hline$F_{5}=0.273$ & $y=1,20$ & 0.328 \\
\hline
\end{tabular}

Selanjutnya perhatikan gambar berikut ini :

Dengan mengambil Guling dititik A, maka momen-momen tersebut dihitung dan di peroleh hasil yang sesuai dengan tabel berikut ini :

Tabel 6 Perhitungan Momen Penampang Pertama

Momen tahanan total $=7,531 \mathrm{tm}$

Momen guling total $=3,967 \mathrm{tm}$

Angka keamanan :

$$
(\text { Fk })=\frac{7,531}{3,967}=1,898>1,5 \ldots \ldots . . .(\text { Aman })
$$

3. Kontrol terhadap gaya geser

Untuk perhitungan gaya geser pada tanggul dimana

faktor keamanan $>1,2$, maka :

$$
\begin{aligned}
& \sum V=8,165 \\
& H=4,518
\end{aligned}
$$

$\mathrm{Fk}=\frac{\sum V . f}{\sum H} \ldots \ldots \ldots \ldots \ldots \ldots . . . \mathrm{f}=$ koefisien geser $\mathrm{Fk}=\frac{8,165 \times 0,6}{4,518}=1,084<1,2($ tidak aman $)$ Berdasarkan perhitungan diatas Setelah dikontrol stabilitas bangunan pantai terhadap stabilitas guling dan gaya geser maka menghasilkan kondisi aman pada guling yaitu $1,898>1,5$ dan kondisi tidak aman pada gaya geser yaitu $1,08<1,2$.

\section{Tampang lintang kedua tanggul}

Tampang lintang kedua dari tanggul tembok berlin dapat dilihat pada gambar di bawah ini :

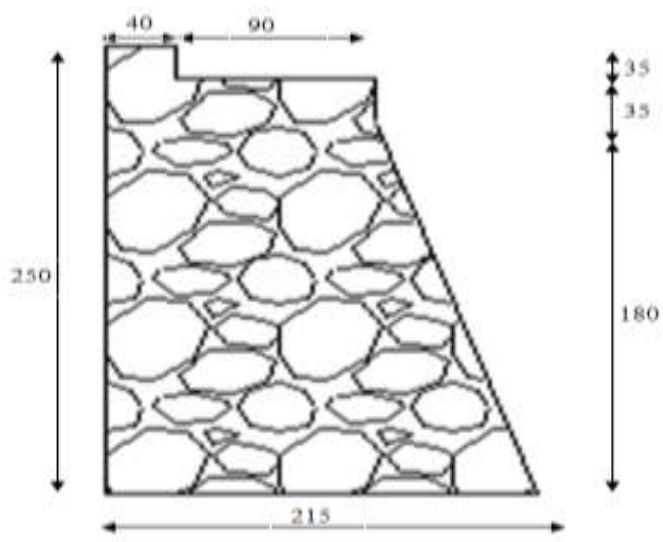

Gambar 9 Tampang lintang kedua dari tanggul tembok berlin

\section{Kontrol stabilitas tanggul}

1. Stabilitas tanggul terhadap gaya-gaya yang bekerja pada tanggul

Stabilitas tanggul terhadap gaya-gaya yang bekerja pada tanggul akan dapat ditinjau bila tanggul dianggap dapat terguling, dengan menganggap bahwa tubuh tanggul merupakan suatu kesatuan. Gaya-gaya yang bekerja pada tanggul dan berbahaya terhadap guling yaitu:

a. Gaya akibat beban sendiri.

b. Tekanan Hidrostatis 
ISSN 1979-7450

c. Gempa Bumi

a. Berat sendiri tanggul

$\mathrm{W}=$ Luas $\times \gamma$ tanah

$W_{1}=2,50 \times 0,40 \times 2,00=2,00 \mathrm{t} / \mathrm{m}$

$W_{2}=2,15 \times 0,90 \times 2,00=3,87 \mathrm{t} / \mathrm{m}$

$W_{3}=1 / 2 \times 1,8 \times 0,85 \times 2,00=1,53$

$\mathrm{t} / \mathrm{m}$

Jadi $\mathrm{W}$ total $=W_{1}+W_{2}+W_{3}+W_{4}=$ $7,385 \mathrm{t} / \mathrm{m}$

b. Tekanan Hidrostatis

$$
\begin{aligned}
& W H_{1}=1 / 2 \times \gamma \text { air } \times h^{2} \\
& W H_{1}=1 / 2 \times 1,025 \times 1,8^{2}=1,66 \mathrm{t} / \mathrm{m} \\
& W_{4}=1 / 2 \times \gamma \text { air } \times \text { a } \times \mathrm{t} \\
& W_{4}=1 / 2 \times 1,025 \times 0,85 \times 1,8=0,78 \mathrm{t} / \mathrm{m}
\end{aligned}
$$

c. Pengaruh gempa

Dengan mengambil harga koefisien gempa 0,20 sampai 0,35 maka komponen-komponen horizontal beban gempa di hitung sebagai berikut:

$m \cdot a=e \cdot(m \cdot g)$

Dimana :

$$
\begin{array}{ll}
\mathrm{M} & =\text { massa } \\
\mathrm{A} & =\text { percepatan horizontal } \\
\mathrm{E} & =0,1-0,35 \\
\mathrm{G} & =\text { Grafitasi }
\end{array}
$$

Dengan mengambil $m \cdot a=F$ dan $m \cdot g=$ $G=W$

$$
\begin{aligned}
& F_{1}=2 \times 0,35=0,7 \mathrm{t} / \mathrm{m} \\
& F_{2}=3,87 \times 0,35=1,3545 \mathrm{t} / \mathrm{m} \\
& F_{3}=1,53 \times 0,35=0,5355 \mathrm{t} / \mathrm{m} \\
& F_{4}=0,78 \times 0,35=0,273 \mathrm{t} / \mathrm{m}
\end{aligned}
$$

2. Kontrol Terhadap Stabilitas Guling Konstruksi tanggul akan aman terhadap guling, apabila memenuhi persamaan berikut:

$\mathrm{Fk}=\frac{M T}{M G} \geq 1,50$

Dimana :

$$
\begin{array}{ll}
\text { MT } & =\text { Momen Tahan } \\
\text { MG } & =\text { Momen Guling } \\
\text { Fk } & =\text { Faktor Keamanan }
\end{array}
$$

Selanjutnya perhatikan gambar berikut ini : Dengan mengambil Guling dititik A, maka momen-momen tersebut dihitung dan di peroleh hasil yang sesuai dengan tabel berikut ini :
Tabel 7. Perhitungan Momen Penampang Kedua

\begin{tabular}{ccc}
$\begin{array}{l}\text { Gaya } \\
\left(\mathrm{t} / \mathrm{m}^{1}\right)\end{array}$ & $\begin{array}{l}\text { Jarak } \\
(\mathrm{m})\end{array}$ & $\begin{array}{l}\text { Momen } \\
(\mathrm{tm})\end{array}$ \\
\hline \multicolumn{3}{c}{ Akibat Beban Sendiri } \\
\hline$W_{1}=2,00$ & $\mathrm{x}=0,20$ & 0,4 \\
$W_{2}=3,87$ & $\mathrm{x}=0,85$ & 3,2895 \\
$W_{7}=1,53$ & $\mathrm{x}=1,5833$ & 2,4224 \\
\hline \multicolumn{3}{c}{ Akibat Gaya Hidrostatis } \\
\hline$W_{4}=0,78$ & $\mathrm{x}=1,8667$ & 1,456 \\
$W H_{1}=1,66$ & $\mathrm{y}=0,60$ & 0,996 \\
\hline \multicolumn{3}{c}{ Akibat Beban Gempa } \\
$F_{1}=0,7$ & $\mathrm{y}=1,25$ & 0,875 \\
$F_{2}=1,3545$ & $y=1,025$ & 1,3884 \\
$F_{2}=0,5355$ & $\mathrm{y}=0,60$ & 0,3213 \\
$F_{4}=0,273$ & $\mathrm{y}=1,20$ & 0,3276 \\
\hline
\end{tabular}

Momen tahanan total $=7,5679 \mathrm{tm}$

Momen guling total $=3,9083 \mathrm{tm}$

Angka keamanan $(\mathrm{Fk})=\frac{7,5679}{3,9083}=$

$$
1,936>1,5 \ldots \ldots \ldots . .(\text { Aman })
$$

3. Kontrol terhadap gaya geser

Untuk perhitungan gaya geser pada tanggul dimana

faktor keamanan >1,2, maka :

$\sum V=8,18$
$\sum H=4,523$

$\mathrm{Fk}=\frac{\sum V \cdot f}{\sum H} \ldots \ldots \ldots \ldots . \mathrm{f}=$ koefisien geser

$\mathrm{Fk}=\frac{8,18 \times 0,6}{4,523}=1,085<1,2($ tidak aman $)$

Berdasarkan perhitungan diatas Setelah dikontrol stabilitas bangunan pantai terhadap stabilitas guling dan gaya geser maka menghasilkan kondisi aman pada guling yaitu $1,936>1,5$ dan kondisi tidak aman pada gaya geser yaitu $1,085<1,2$.

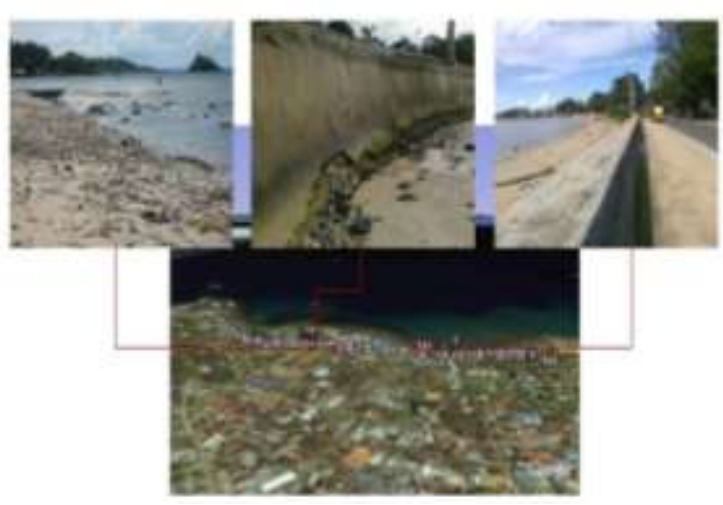

Gambar 10 Peta Citra dan Kondisi Tanggul dan Pantai dofior kota Sorong 
ISSN 1979-7450

\subsection{Analisa Dimensi Bangunan Pantai}

Di Pantai Dofior Kota Sorong telah terdapat bangunan pantai yaitu tembok laut tetapi alangkah baiknya ditambah bangunan tambahan yaitu Breakwater didepan bangunan pantai lama untuk menjaga stabilitas pantai, lebih melindungi daratan dan memperindah pantai karena Pantai Dofior merupakan kawasan wisata.

Dari hasil analisa pasang surut dan tinggi gelombang didapat :

a. $\mathrm{HWL}=2,1 \mathrm{~m}$

b. $\quad \mathrm{LWL}=0,2 \mathrm{~m}$

c. $\mathrm{MWL}=1,7$

d. Tinggi Gelombang $(\mathrm{H})=3,22 \mathrm{~m}$ (gelombang periode ulang 50 tahun)

e. Perioda Gelombang $(\mathrm{T})=9$ detik

Kemudian Perhitungan yang harus dilakukan pada Bangunan pelindung pantai breakwater yaitu sebagai berikut :

1. Berat butir lapis lindung

Berat batu lapis lindung dihitung dengan rumus Hudson berikut ini :

Untuk lapis lindung dari batu $\left(K_{D}=4\right)$ :

$$
\begin{gathered}
w=\frac{\gamma_{r} H^{3}}{K_{D}\left(S_{r}-1\right)^{3} \cot \theta} \\
S_{r}=\frac{2,65}{1,03}=2,573 \\
w=\frac{2,65 \times 3,22^{3}}{4(2,573-1)^{3} 2}=\frac{88,47}{31,14} \\
=0,3998 \text { ton }=2,8 \text { ton }
\end{gathered}
$$

Untuk lapis lindung dari tetrapod $\left(K_{D}=8\right)$ :

$$
w=\frac{2,65 \times 3,22^{3}}{8(2,573-1)^{3} 2}=1,42 \text { ton }
$$

Apabila di dekat lokasi terdapat persediaan batu dengan berat seperti dalam hitungan diatas dalam jumlah banyak, maka digunakan lapis lindung dari batu pecah. Untuk selanjutnya digunakan lapis lindung batu pecah dengan berat 2,8 ton.

2. Lebar puncak pemecah gelombang Lebar puncak pemecah gelombang $\mathrm{n}=$ 3(minimum)

$$
\begin{aligned}
& B=n k \Delta\left[\frac{W}{\gamma_{r}}\right]^{1 / 3} \\
& \rightarrow \text { dari tabel koefisien lapis } \\
& k \Delta=1,15(\text { batu alam }) \\
& B=3 \times 1,15\left[\frac{2,8}{2,65}\right]^{1 / 3}=3,5 \mathrm{~m}
\end{aligned}
$$

3. Tebal lapis lindung

Tebal lapis lindung dihitung dengan rumus berikut :

$$
\begin{aligned}
& t=n k \Delta\left[\frac{W}{\gamma_{r}}\right]^{1 / 3} \\
& t=2 \times 1,15\left[\frac{2,8}{2,65}\right]^{1 / 3}=2,3 \mathrm{~m}
\end{aligned}
$$

4. Jumlah batu pelindung

Jumlah butir batu pelindung tiap satuan luas $\left(10 \mathrm{~m}^{2}\right)$ di hitung dengan rumus berikut:

$$
\begin{gathered}
N=A n k_{\Delta}\left[1-\frac{p}{100}\right]\left[\frac{\gamma_{r}}{W}\right]^{2 / 3} \\
N=10 \times 2 \times 1,15\left[1-\frac{37}{100}\right]\left[\frac{2,65}{2,8}\right]^{2 / 3} \\
=14
\end{gathered}
$$

5. Panjang gelombang (Lo)

$$
\mathrm{Lo}=1,56 \mathrm{~T}^{2}=1,56(9)^{2}=126,36 \mathrm{~m}
$$

6. Bilangan Irribaren

Dalam perencanaan $\operatorname{tg} \theta=0,5$

Run up dapat dihitung dengan fungsi

bilangan irribaren :

$$
\begin{aligned}
\operatorname{Ir} & =\operatorname{tg} \theta /(\mathrm{H} / \mathrm{Lo})^{0,5} \\
& =0,5 /(3,22 / 126,36)^{0,5} \\
& =3,1
\end{aligned}
$$

7. Dengan menggunakan grafik run up gelombang :

Untuk material dari batu pecah (Quary Stone) didapat :

$$
\begin{aligned}
& \mathrm{Ru} / \mathrm{H}=1,25 \rightarrow \mathrm{Ru}=1,25 \mathrm{x} \\
& 3,22 \mathrm{~m}=4,025 \mathrm{~m}
\end{aligned}
$$

8. Tinggi bangunan dinding pantai

Didapat dengan memperhitungakan tinggi jagaan atau tinggi kebebasan $=0,5 \mathrm{~m}$ dan pengaruh pasang tertinggi pada tepi pantai tersebut sebesar $=2,1 \mathrm{~m}$.

Tinggi dinding pantai

$$
\begin{aligned}
& =\mathrm{HWL}_{\text {tepi pantai }}+\mathrm{Ru}+\text { tinggi kebebasan } \\
& =2,1+4,025+0,5 \\
& =6,6 \mathrm{~m}
\end{aligned}
$$

\section{PENUTUP}

\subsection{Kesimpulan}

1. Berdasarkan data pasang surut oleh Dinas Hodro-Oceanografi TNI-AL dapat disimpukan bahwa tipe pasang surut yang di kota Sorong adalah tipe campuran dominan ganda

2. Dengan menggunakan data angin selama 3 tahun dari tahun 2008 sampai 2010 menghasilkan 
ISSN 1979-7450

gelombang yang dominan pada arah Barat yaitu sebesar 8,28\% dan Barat Daya yaitu 5,97\%.

3. Setelah dikontrol stabilitas bangunan pantai terhadap stabilitas guling dan gaya geser, maka menghasilkan kondisi tidak aman pada geser dan kondisi aman pada gaya guling.

4. Bangunan pantai di pantai dofior yaitu tembok laut. Kondisi bangunan ini sudah mengalami penurunan ini terlihat dikaki bangunan yang sudah tergerus oleh ombak, apabila tidak segera diperbaiki maka tembok tersebut akan roboh dan jalan akan terancam.

\subsection{Saran}

1. Perlu dilakukan perbaikan pada tembok laut tersebut dan untuk melindungi tergerusnya kaki tembok perlu dipasang rip-rap.

2. Perlunya penanganan masalah sampah.

3. Perlunya perencanaan yang mendetail dari tipe bangunan pengaman pantai (breakwater) di depan pantai dofior.

\section{DAFTAR PUSTAKA}

Anonimous, Definisi dan Klasifikasi (file PDF)

Anonimous, Tugas Teknik Pantai, Prodi Teknik Sipil UNAMIN, Sorong

Anonimous, Tugas Teknik Pantai, Bangunan Pelindung Pantai, Universitas Sumatera Utara. (file PDF)

Catatan dan bahan kuliah Teknik Pantai Muh. Tasmin dengan dosen Bapak Faried desembardi, ST.

Dewi Afrianti Arief, Achsan, Tugas Akhir, Tinjauan Penanggulangan Banjir Kali Oba Maluku Utara, Universitas Hasanuddin.

Martius, Tesis, Studi Konsep Penanganan Erosi Pantai Cerocok Painan Kabupaten Pesisir Selatan Propinsi Sumatera Barat, (Institut Teknologi Bandung) (file PDF)

Triatmojo,Bambang.1999. Teknik Pantai. Yogyakarta:Beta Offset.

http://syahrin88.wordpress.com/2010/09/09/ bangunan-pelindung-pantai/
http://id.m.wikipedia.org/wiki/pantai?wasRe directed=true

http://wahyuancol.wordpress.com/2008/06/0 5/erosi-pantai/

http://yanuarmulia.student.umm.ac.id/2010/

07/08/tembok-dofior-atau-tembok-

berlin/

http://scribd.com/document/38524680

http://weblakes.com/lakewrpl.html

http://cid-

7b3122134b7f51a8.office.live.com/self. aspx/Public/catatan\%20juru\%20ukur/X LS-SVY-05.zip

http://cadex.wordpress.com/2011/01/05/xlssvy-05-form-excel-untuk-perhitunganpasut-dengan-hitung-kwadrat-terkecil/. 